\title{
вмј Global Health Long-term change in the prevalence of intimate partner violence: a 20-year follow-up study in León, Nicaragua, 1995-2016
}

\author{
Mary Ellsberg (D) , ${ }^{1,2}$ William Ugarte, ${ }^{3,4}$ Junior Ovince, ${ }^{1}$ Alexandra Blackwell, ${ }^{1}$ \\ Margarita Quintanilla ${ }^{5}$
}

To cite: Ellsberg M, Ugarte W, Ovince J, et al. Long-term change in the prevalence of intimate partner violence: a 20-year follow-up study in León, Nicaragua, 19952016. BMJ Global Health 2020;5:e002339. doi:10.1136/ bmjgh-2020-002339

Handling editor Seye Abimbola

Received 24 January 2020

Revised 3 March 2020

Accepted 7 March 2020
Check for updates

C Author(s) (or their employer(s)) 2020. Re-use permitted under CC BY-NC. No commercial re-use. See rights and permissions. Published by BMJ.

${ }^{1}$ Global Women's Institute, The George Washington University, Washington, DC, USA

${ }^{2}$ Department of Global Health, Milken Institute School of Public Health, The George Washington University, Washington, DC, USA ${ }^{3}$ Faculty of Health Sciences, National Autonomous University of Nicaragua-León, León, León, Nicaragua

${ }^{4}$ Department of Women's and Children's Health, Uppsala University, Uppsala, Sweden ${ }^{5}$ Managua, Nicaragua

Correspondence to Dr Mary Ellsberg; mellsberg@gwu.edu

\section{ABSTRACT}

Introduction Although intimate partner violence (IPV) affects an estimated one out of three women globally, evidence on violence prevention is still scarce. No studies have measured long-term change in larger populations over a prolonged period.

Methods The aim of this study was to measure changes in the prevalence of IPV in León, Nicaragua, between 1995 and 2016. The 2016 study interviewed 846 ever-partnered women aged 15 to 49 regarding experiences of physical, sexual and emotional IPV. These findings were analysed together with comparable data collected from 354 women in 1995. Multivariate logistic regression modelling was carried out on a pooled data set to identify differences between the two studies while controlling for potential confounding factors.

Results Lifetime physical IPV decreased from 54.8 to 27.6 per cent (adjusted OR (AOR) $0.37 ; 95 \% \mathrm{Cl} 0.28$ to 0.49 ) and 12-month prevalence of physical IPV decreased from 28.2 to 8.3 per cent (AOR $0.29 ; 95 \% \mathrm{Cl} 0.20$ to 0.42 ), respectively. Similar decreases were found in lifetime and 12-month emotional IPV. No significant difference was found in the prevalence of lifetime sexual violence between the two time periods.

Conclusions The results suggest that the reduction in IPV was not due to demographic shifts, such as increased education or age, but reflects a true decrease in the prevalence of IPV. The decrease is not likely to have occurred on its own, and may be attributable to multisectoral efforts by the Nicaraguan government, international donors and the Nicaraguan women's movement to increase women's knowledge of their rights, as well as access to justice and services for survivors during this time period.

\section{INTRODUCTION}

During the last 25 years since the landmark Fourth World Conference on Women was held in Beijing, efforts to address violence against women and girls (VAWG) internationally have increased; nevertheless, VAWG remains widespread. The WHO estimates that $35 \%$ of women globally experience sexual

\section{Key questions}

What is already known?

- The prevention of intimate partner violence (affecting one in three women globally) has been identified as an urgent priority in the Sustainable Development Goals, and as a necessary step for achieving other development goals, such as poverty reduction and improving the health and well-being of communities.

- Multisectoral strategies that increase access to justice and comprehensive services for survivors and transform restrictive gender norms are considered essential for achieving large scale and sustained reductions in intimate partner violence (IPV); however, most studies to date have measured only short-term change in small-scale programmes or populations.

What are the new findings?

- This study is the first to measure population-level change in the prevalence of IPV over a 20-year period.

- By using multivariate modelling on a pooled data set controlling for potential confounding variables, we were able to show that the changes in León were not simply due to demographic shifts over time.

- It is likely that the well-documented transformations in laws and policies, as well as widespread awareness campaigns and programmes to transform social norms, led by the broad-based women's movement, have contributed to the decrease in violence over the period.

What do the new findings imply?

- The findings show that violence against women may be prevented on a large scale through structural interventions.

- Future research and practice should focus on bringing successful programmes to scale; in particular multisectoral programmes that combine community mobilisation and rights-based strategies with sector-based prevention programmes.

and/or physical intimate partner violence (IPV) or non-partner sexual violence at some point in their lives. ${ }^{1}$ A recent review of the effectiveness of interventions to prevent 
VAWG indicates that the most effective communitybased interventions generally include multiple components, and address structural drivers of VAWG, including restrictive gender norms. Nonetheless, the evidence base on population-based prevention strategies is still very limited, and robust evidence is needed to determine how structural interventions can contribute to the prevention of VAWG on a large scale. ${ }^{2}$

The first population-based study in Central America to provide robust prevalence estimates on physical and sexual violence against women by intimate partners was conducted in Nicaragua in 1995. The study included 488 women aged 15 to 49 from the municipality of León, Nicaragua's second largest city. The findings revealed that, among ever-partnered women, more than half (52\%) had experienced physical violence by a current or former intimate partner during their lifetime, and $27 \%$ of women had experienced violence in the 12 months prior to the interview. Overall, $15 \%$ of ever-pregnant women experienced violence during pregnancy, and $33 \%$ of abused women experienced physical, sexual and emotional violence. ${ }^{34}$

As one of the earliest in-depth studies on VAWG conducted in low- and middle-income countries, the Nicaraguan study had an impact on the emerging global VAWG research agenda. The study informed the development of the WHO Multi-Country Study on Women's Health and Domestic Violence against Women, the WHO Ethical and Safety Guidelines for Researching Violence against Women and the Domestic Violence Module of the Demographic and Health Surveys (DHS), which was piloted in Nicaragua in 1998 and has since been used in over 40 countries. ${ }^{5-7}$ In addition, the study served as the baseline for a series of epidemiological studies that provided evidence of the impact of IPV on the health of women and children in Nicaragua, including low-birth weight, adverse pregnancy outcomes, infant and child mortality, adolescent pregnancy, sexual and reproductive health and mental health. ${ }^{8-11}$

The study results were also disseminated widely throughout Nicaragua through national meetings, newspapers, radio and television interviews and reprints in local journals, and helped garner political support for the first Domestic Violence Law (Law 230), which was passed unanimously by the National Assembly in $1996 .{ }^{12}$ This reform was followed by a Ministerial Decree (No 67 - 96) from the Ministry of Health, which declared that violence against women is a significant health problem in Nicaragua and health providers have an obligation to provide compassionate care to survivors of violence. During the two decades since the study was released, a number of comprehensive efforts were implemented in Nicaragua to prevent VAWG. Starting in 2001, the Nicaraguan Women's Institute implemented a 5-year National Plan for the Prevention of Domestic and Sexual Violence, which involved multisectoral collaboration among the Ministry of Health, National Police, Ministry of Family, Nicaraguan Institute of Statistics and Census, Ministry of
Education, Culture and Sports and various universities and civil society organisations. The national plan aimed to develop institutional capacity to ensure VAWG survivors were able to access key services, improve the overall understanding of the situation of VAWG in Nicaragua and implement effective interventions to prevent VAWG ${ }^{13}$

In addition to the legislative reforms, women's access to justice was improved through the establishment of women and children's police stations, or Comisarias de la Mujer y la Niñez, with specialised female police officers and social workers. As of 2010, there were a total of 59 Comisarias in Nicaragua, providing women and children who experienced domestic or sexual violence with a unique entry point into the police and justice system. A 2000 study found that over 98 per cent of women surveyed knew of the Comisarias and 77 per cent believed they have reduced levels of VAWG. ${ }^{13} 14$

The new laws, policies and services were made possible due to the continuous advocacy of women's rights activists organised in the National Network of Women against Violence (Red Nacional de Mujeres contra la Violencia). The Network was founded in 1992 and has advocated for increased access to services and justice for survivors of violence (including safe abortion) through key legislative and policy reforms. ${ }^{12}$ Through its members, the Network also provides support in the form of crisis centres, shelters, medical and legal counselling to survivors of violence throughout the country. Throughout the 90's the Network carried out public awareness campaigns to denounce the culture of impunity around VAWG and to encourage women to exercise their rights as citizens. One member of the network, the local non-governmental organisation (NGO) Puntos de Encuentro, produced an award winning 'edutainment' show, Sexto Sentido, that specifically addressed domestic violence, rape, and child sexual abuse. The show was shown to be effective in raising awareness about the laws and services addressing violence. $^{15}$ In 2012, the women's movement lobbied successfully for passage of a new Violence against Women Law (Law 779) to strengthen protections for survivors of VAWG by eliminating key obstacles in the path to justice. ${ }^{1617}$

After the 1995 domestic violence study, three waves of DHS data have collected information on intimate partner violence, in 1998, 2005/2006 and 2011/2012. ${ }^{18-20}$ Although the DHS data indicate a downward trend in the prevalence of IPV in Nicaragua, these figures are considered to be underestimates of the true prevalence of IPV in Nicaragua, due to methodological inconsistencies in the way violence was measured and reported. ${ }^{21}$ In the absence of an in-depth dedicated VAWG survey, it has not been clear whether the reported decrease was due to a true reduction in violence, or to other factors, such as demographic shifts or methodological issues.

The aim of this study was to estimate the current prevalence and characteristics of physical, sexual and emotional violence by a current or former intimate partner in the municipality of León, Nicaragua, and to compare these 


\begin{tabular}{|c|c|}
\hline 1995 & 2016 \\
\hline \multicolumn{2}{|l|}{ Introduction } \\
\hline $\begin{array}{l}\text { During the last year, in a moment of conflict or } \\
\text { discussion with your current or ex-partner, how often } \\
\text { did he do the following: }\end{array}$ & $\begin{array}{l}\text { The next questions are about things that happen to many women and } \\
\text { that your current partner, or any other partner may have done to you. } \\
\text { Has your current husband/partner, or any other partner ever... }\end{array}$ \\
\hline \multicolumn{2}{|l|}{ Emotional violence } \\
\hline Yell or insult you? & Insulted you or made you feel bad about yourself? \\
\hline Do something to humiliate you? & Belittled or humiliated you in front of other people? \\
\hline \multirow[t]{2}{*}{ Threaten to hit you? } & Done things to scare or intimidate you on purpose? \\
\hline & Threatened to hurt you or someone you care about? \\
\hline \multicolumn{2}{|l|}{ Physical violence } \\
\hline Throw something at you? & Slapped you or thrown something at you that could hurt you? \\
\hline Push or shove you? & Pushed you or shoved you or pulled your hair? \\
\hline Slap you? & Hit you with his fist or with something else that could hurt you? \\
\hline Kick, bite or hit you with his fist? & Kicked you, dragged you or beat you up? \\
\hline Beat you up? & Choked or burnt you on purpose? \\
\hline Threaten you with a knife or gun? & $\begin{array}{l}\text { Threatened to use or actually used a gun, knife or other weapon } \\
\text { against you? }\end{array}$ \\
\hline \multicolumn{2}{|l|}{ Use a knife or gun on you? } \\
\hline \multicolumn{2}{|l|}{ Sexual violence } \\
\hline \multirow[t]{3}{*}{$\begin{array}{l}\text { Force you to have sex or do something sexual } \\
\text { against your will? }\end{array}$} & $\begin{array}{l}\text { Physically force you to have sexual intercourse when you did not } \\
\text { want to? }\end{array}$ \\
\hline & $\begin{array}{l}\text { Did you ever have sexual intercourse you did not want to because } \\
\text { you were afraid of what your partner or any other partner might do? }\end{array}$ \\
\hline & $\begin{array}{l}\text { Did your partner or any other partner ever force you to do something } \\
\text { sexual that you found degrading or humiliating? }\end{array}$ \\
\hline \multicolumn{2}{|l|}{ Follow-up questions } \\
\hline \multirow[t]{2}{*}{ Lifetime experiences of each act of violence } & 12-month experiences of each act of violence \\
\hline & Frequency of each act of violence (lifetime and 12 month) \\
\hline
\end{tabular}

with earlier estimates from 1995 to determine whether there have been changes in IPV prevalence over a 20-year period.

\section{METHODS}

Both the 1995 and the 2016 studies used a mixedmethods methodology, including a household survey and qualitative research. Both studies were designed and carried out by the same principal investigator (ME) and national research team at the Medical School of the National Autonomous University at Leon (UNAN-León). The qualitative results will be presented separately. The 1995 study used the Conflict Tactics Scale to measure physical and emotional violence by a current or former intimate partner, with an additional question on lifetime experiences of sexual violence. ${ }^{22}$ The 2016 study used the WHO Multi-Country Study on Women's Health and Domestic Violence Against Women Instrument (V.12.2) to measure physical, emotional and sexual violence. ${ }^{23}$ Table 1 presents the questions used to measure IPV in both studies. With the exception of sexual violence in the 1995 study, ${ }^{16}$ which only asked about lifetime experiences of violence, all other acts were measured as lifetime experiences as well as in the 12 months prior to the interview. Women who reported experiencing one or more acts of any type of violence by a current or former partner were classified as having experienced IPV. In addition to questions about experiences of violence, both studies asked about women's physical and mental health, and responses to violence and satisfaction with services. The 2016 study also included questions about non-partner sexual assault, disability, attitudes regarding gender norms and domestic violence laws, as well as exposure to violence prevention campaigns and programmes. These results will be presented elsewhere. In both studies, face-to-face interviews were conducted in respondents' homes by trained female interviewers using paper questionnaires in 1995, and electronic tablets in 2016. Interviewers with experience in collecting data on sensitive issues were recruited and received an additional 4 week training conducted, in both cases, by the primary investigator (ME). 


\section{Study population and sample}

The study was carried out in the municipality of León, the second largest city in Nicaragua. In 1995 the population of León was 195000 and by 2016 it was $206264 .{ }^{24}$ Both samples were selected from the same master sample to ensure a self-weighted random sample representing León municipality. The 1995 study was nested in a Health and Demographic Surveillance System (HDSS) in León, which was created in $1992 .{ }^{25}$ It was set up by means of cluster sampling and represented approximately $30 \%$ of the population of León municipality. The 1995 sample was a random selection of 566 women aged 15 to 49 who were registered in the HDSS. If the selected woman had moved to a new home or town, efforts were made to locate and interview her.

In the 2016 study, the sample size was estimated at 1920, with the goal of obtaining 1500 completed interviews (the recommended sample size for WHO IPV studies), and allowing for non-response. The study used a multistage stratified sample design. The HDSS currently includes 12163 houses and 662 enumeration areas (EA), stratified by the three administrative territories of León, each with urban and rural EAs. The EAs were subdivided into 2623 segments (1673 urban and 950 rural), each containing five houses in the urban areas and four houses in the rural areas. The difference in sampling intervals was a safety measure to reduce the likelihood of other household members learning about the subject of the interview in more densely populated areas. ${ }^{6}$ For the same reason, only one eligible woman was interviewed in each household. In the first stage, 1920 (600 rural and 1320 urban) segments were randomly selected using probability proportional to size. The enumeration maps were updated in person prior to data collection, and it was found that 39 intervals no longer existed, leaving a total of 1881 households in the sample. In each segment, one household was randomly selected. The questionnaire was administered in two parts. The first part was a household questionnaire which was administered to any adult member of the household. This included socio-economic data, as well as a listing of all eligible women (between 15 to 64$)$ living in the household. If there was more than one eligible woman in a household, one woman was randomly selected to be interviewed in private using the individual questionnaire. The study was introduced to the household as a study on women's health; only the selected woman was told about the true purpose of the study. No substitutions were made in the case of nonresponse or households with no eligible women. At least three attempts were made to contact eligible women, including at night and on weekends in both studies.

\section{Patient and public involvement}

The 1995 study was carried out as a joint partnership between UNAN-León, Umeå University and the Nicaraguan Network of Women against Violence. All partners participated in the development of the study objectives, design, analysis, reporting and dissemination of the findings. In addition, members of the Network supported interviewer training and providing referrals for participants who had experienced violence. The 2016 study was a collaboration between George Washington University, UNAN-León and InterCambios, a Nicaraguan NGO with expertise in VAWG. Prior to conducting the study, meetings were held with women's rights activists, including members of the Nicaraguan Network of Women against Violence, both in Managua and León, to assess the feasibility, safety and relevance of the study, particularly given the increasing restrictions being placed on civil society by the Nicaraguan Government. Several of these groups collaborated with the study by providing referral services to survivors of violence and participating in focus group discussions and in-depth interviews. Preliminary findings were discussed with local stakeholders to support interpretation of the results, and to guide further analysis of the data.

\section{Ethical considerations}

Measures were taken in both the 1995 and the 2016 studies to minimise any potential distress or harm to either the research team or the participants as a result of disclosing violence. ${ }^{21}{ }^{26}$ Verbal informed consent was obtained in both studies. The research adhered to the WHO safety and ethical guidelines,${ }^{626}$ including interviewing only one woman per household, ensuring complete privacy and confidentiality and providing information and referrals to all participants. Interviewer training was conducted over a 4-week period, and included knowledge of genderbased violence, and crisis management. Interviewers were offered counselling and emotional debriefing sessions were carried out regularly to prevent vicarious trauma among field staff. Earlier research in Nicaragua has shown that these measures contribute to participant safety as well as increased disclosure of violence among respondents. ${ }^{21} 26$

\section{Data analysis}

Both descriptive and multivariate statistical analysis was conducted using SPSS V.26. Bivariate and multivariate logistic regression analysis was performed on each data set individually to identify potential risk and protective factors for IPV. Thereafter, the files were merged using identical variables and the same analysis was performed on a pooled data set. The electronic files from the 1995 study were no longer available, but paper copies of the original completed questionnaires were located and re-entered into an electronic database. A few differences were found between the reanalysed data-set and the published results from the 1995 study, possibly due to revised definitions of partnership. Using the criteria for partnership established by the WHO Multi-Country Study, which included cohabiting or married women, but not women in dating or non-cohabiting relationships, only 354 of the women were classified as ever-partnered, compared with 360 women in the original analysis. Nevertheless, the overall results with regard to demographic characteristics 
and prevalence of violence were nearly identical, with the exception of urban/rural residence. Information on residence could not be identified in 48 cases because some neighbourhoods (both urban and rural) were destroyed by natural disasters in the intervening years and were no longer included in the updated sampling frame. The missing values were addressed comparing two different approaches. The first approach excluded the 48 cases with missing values (listwise deletion) from the analysis. The main risk of this approach is that the results of the pooled analysis could be biased due to the non-random nature of the missing values. ${ }^{27}$ In addition, the loss of almost $14 \%$ of the sample could significantly reduce its analytical power. The second approach used imputation, by recoding missing values for the residence variable as belonging to the rural zone. Because the prevalence of physical and sexual partner violence was lower in the rural area in both the 1995 and 2016 studies, any potential bias would tend to dilute the association between residence and IPV, rather than increasing it. The results of both models were similar, and residence was not significantly associated with IPV in either of the pooled models, so the imputed data set was used in the comparative analysis.

Lifetime experiences of physical, sexual and emotional IPV, as well as 12-month prevalence of physical and emotional IPV were selected as the main dependent variables. The main independent variable was a dummy variable created to represent the time period of the study. Other independent variables were selected based on previous literature on risk and protective factors for IPV as well as pragmatic considerations. ${ }^{28}{ }^{29}$ The purpose of the present analysis was not to identify all potential risk and protective factors for IPV in León (for example, parity, partnership status, attitudes towards violence, family support, childhood experiences of violence, disability, alcohol use by partner, etc), but rather, to analyse changes in IPV prevalence while controlling for potential confounders. Therefore, selection was limited to demographic characteristics representing changes in the population structure that could be associated with IPV (education, age, residence, partnership status), and where identical measures were available in both data sets. Although poverty was measured in both studies, the methods for defining poverty have changed, and therefore they could not be compared.

\section{RESULTS}

The 1995 study completed interviews with 488 women aged 15 to 49 , of whom 360 were classified as everpartnered in the historical data, and 354 in the re-entered data. Of the 566 women in the original sample, 78 had moved away and could not be located. No women refused to be interviewed. The response rate for this study was 86 per cent.

Table 2 presents the household and individual response rates for the 2016 survey. Out of 1881 households in the sample, 1399 interviews were completed with women aged 15 to 64 . Of these, 1195 women had ever had an intimate partner. The household response rate was 95 per cent and the individual response rate was 97 per cent. Although the study included women aged 15 to 64 , only ever-partnered women aged 15 to $49(n=876)$ were included in this analysis for comparability with the 1995 data set.

Table 3 compares the demographic characteristics of ever-married women who participated in the 1995 and 2016 studies, respectively. Demographic and historical trends over the last 20 years have resulted in a number of significant differences between the two samples. The municipal government of León continues to use the same geographical boundaries for urban and rural settlements as in 1995; however, the population has expanded over the years. Whereas $18 \%$ of women in the 1995 study lived in a zone classified as 'rural', this figure grew to $33 \%$ of the sample in 2016. Although some rural areas are still

Table 2 Household and individual sample obtained and response rates, León, Nicaragua, 2016

\begin{tabular}{|c|c|c|}
\hline & \multicolumn{2}{|l|}{2016} \\
\hline & $\mathbf{N}$ & $\%$ \\
\hline Total number of households in the sample & 1881 & 100 \\
\hline Dwelling vacant or destroyed & 72 & 4 \\
\hline Total number of true (eligible) households visited & 1809 & 100 \\
\hline Household members absent & 32 & 2 \\
\hline Refused at household level & 68 & 4 \\
\hline Household interview completed (household response rate is based on true households) & 1709 & 95 \\
\hline No eligible woman in household & 271 & 16 \\
\hline Selected woman not available (after three visits) & 7 & 1 \\
\hline Selected woman incapacitated & 7 & 1 \\
\hline Refused by selected woman & 22 & 2 \\
\hline Does not want to continue (partially completed) & 3 & 0 \\
\hline Completed individual interviews (individual response rate is based on households with selected eligible woman) & 1399 & 97 \\
\hline
\end{tabular}


Table 3 Demographic characteristics of ever-partnered women aged 15 to 49 in 1995 and 2016, León Municipality, Nicaragua*

\begin{tabular}{|c|c|c|c|c|}
\hline & \multicolumn{4}{|c|}{ Study period } \\
\hline & \multicolumn{2}{|c|}{$1995(n=354)$} & \multicolumn{2}{|c|}{$2016(n=876)$} \\
\hline & $\mathbf{N}$ & $\%(95 \% \mathrm{Cl})$ & $\mathbf{N}$ & $\%(95 \% \mathrm{Cl})$ \\
\hline \multicolumn{5}{|l|}{ Age } \\
\hline $15-19$ & 31 & 8.8 (6.1 to 12.0$)$ & 41 & 4.7 (3.4 to 6.2 ) \\
\hline 20-29 & 140 & 39.5 (34.6 to 44.7 ) & 296 & 33.8 (30.7 to 37.0 \\
\hline $30-39$ & 116 & 32.8 (28.0 to 37.8 ) & 275 & 31.4 (27.2 to 33.2 \\
\hline $40-49$ & 67 & 18.9 (15.1 to 23.3$)$ & 264 & 30.1 (27.2 to 33.2 \\
\hline \multicolumn{5}{|l|}{ Residence } \\
\hline Urban & 250 & 70.6 (65.7 to 75.2$) \dagger$ & 568 & 64.8 (61.6 to 67.9$)$ \\
\hline Rural or missing & 104 & 29.4 (24.8 to 34.3$)$ & 308 & 35.2 (32.1 to 38.4 \\
\hline \multicolumn{5}{|l|}{ Education } \\
\hline No education/primary & 187 & 52.8 (47.6 to 58.0$)$ & 279 & 31.9 (28.9 to 35.0 \\
\hline Secondary & 152 & 42.9 (37.9 to 48.1$)$ & 397 & 45.4 (42.1 to 48.7 ) \\
\hline University & 15 & 4.2 (2.5 to 6.7 ) & 199 & 22.7 (20.1 to 25.6 \\
\hline \multicolumn{5}{|l|}{ Partnership status } \\
\hline Currently partnered & 279 & 78.8 (74.3 to 82.8 ) & 755 & 86.2 (83.8 to 88.4 ) \\
\hline Formerly partnered & 75 & $21.2(17.2$ to 25.7$)$ & 121 & 13.8 (11.6 to 16.2 \\
\hline
\end{tabular}

${ }^{*}$ Absolute numbers $(\mathrm{N})$ and percentages with $95 \% \mathrm{Cls}$ are presented.

†This figure is lower than the 1995 published data for the reasons described in the methods section.

quite dispersed, others are more like peri-urban neighbourhoods that have sprung up outside the city limits of León, spurred by greater job opportunities and improved transportation in rural areas. Ever-partnered women in the current sample are older than the women in the 1995 sample, reflecting a national increase in the median age of marriage. They are also more educated, with $23 \%$ of women in 2016 having some university level studies, compared with $4 \%$ in 1995 . The demographic changes over time observed in this study are in line with other demographic studies conducted in Nicaragua. ${ }^{18-20}$

Table 4 presents the prevalence of physical, sexual and emotional violence among ever-partnered women aged 15 to 49 stratified by time period. The 1995 study only measured lifetime experiences of sexual violence, so comparisons of 12-month prevalence were only available for physical and emotional violence.

Between 1995 and 2016, the prevalence of physical partner violence decreased from 55 to 28 per cent. The greatest decrease was seen in the 12-month estimates of physical violence (from 28 to 8 per cent). The prevalence of lifetime and 12-month emotional violence also decreased (from 71 to 43 per cent and 43 to 23 per cent, respectively.) The smallest decrease was found for lifetime sexual violence (from 20 to 15 per cent.)

Table 5 compares the results of the León studies to the three Demographic and Health Surveys conducted in $1998,2005 / 2006$, and 2011/2012, that included a domestic violence module. Between the first DHS carried out in 1998 and the most recent one from 2011, there

Table 4 Prevalence of intimate partner violence in 1995 and 2016, León, Nicaragua*

\begin{tabular}{|c|c|c|c|c|}
\hline & \multicolumn{2}{|c|}{1995} & \multicolumn{2}{|c|}{2016} \\
\hline & \multicolumn{2}{|c|}{ Total women 15-49 ( $n=354)$} & \multicolumn{2}{|c|}{ Total women 15-49 $(n=876)$} \\
\hline & $\mathbf{N}$ & $\%(95 \% \mathrm{Cl})$ & $\mathbf{N}$ & $\%(95 \% \mathrm{Cl})$ \\
\hline Lifetime physical violence & 194 & 54.8 (49.6 to 59.9$)$ & 242 & $27.6(24.7$ to 30.7$)$ \\
\hline Lifetime sexual violence & 72 & 20.3 (16.4 to 24.8$)$ & 132 & $15.1(12.8$ to 17.6$)$ \\
\hline Lifetime emotional violence & 252 & 71.2 (66.3 to 75.7$)$ & 377 & 43.0 (39.8 to 46.3$)$ \\
\hline 12-month physical violence & 100 & 28.2 (23.7 to 33.1$)$ & 73 & $8.3(6.6$ to 10.3$)$ \\
\hline 12-month emotional violence & 151 & 42.7 (37.6 to 47.8$)$ & 204 & 23.3 (20.6 to 26.2$)$ \\
\hline
\end{tabular}

*Absolute values and percentages with corresponding 95\% Cls are given for the proportion of ever-married women aged 15 to 49 who reported intimate partner violence ever in their lifetimes and in the 12 months prior to the interview in 1995 and 2016 . Calculations were made on the individual data sets. 
Table 5 Prevalence of IPV in five different studies among women 15 to 49 in León*

\begin{tabular}{|c|c|c|c|c|c|}
\hline & \multirow{2}{*}{$\begin{array}{l}1995 \\
(n=354)\end{array}$} & \multirow{2}{*}{$\begin{array}{l}\text { DHS } 1998 \\
(n=691)\end{array}$} & \multirow{2}{*}{$\begin{array}{l}\text { DHS 2005/2006 } \\
(n=1057)\end{array}$} & \multirow{2}{*}{$\begin{array}{l}\text { DHS 2011/2012 } \\
(n=1267)\end{array}$} & \multirow{2}{*}{$\begin{array}{l}2016 \\
(n=876)\end{array}$} \\
\hline & & & & & \\
\hline Lifetime physical IPV & 55 & 25 & 26 & 17 & 27 \\
\hline Lifetime sexual IPV & 20 & 8 & 14 & 10 & 15 \\
\hline Lifetime emotional IPV & 71 & $\ldots$ & 53 & 33 & 42 \\
\hline 12-month physical IPV & 28 & 10 & 10 & 7 & 8 \\
\hline 12-month sexual IPV & $\ldots$ & 3 & 4 & 3 & 5 \\
\hline 12-month emotional IPV & 43 & $\ldots$ & 24 & 16 & 23 \\
\hline
\end{tabular}

*DHS figures are based on weighted samples representing ever-partnered women from the Department of León.

DHS, Demographic and Health Surveys; IPV, intimate partner violence.

were decreases in both physical and emotional violence, but not sexual IPV. In nearly all cases, the estimates of IPV from both the 1995 and 2016 studies are higher than the DHS estimates.

Multivariate logistic regression analysis was performed on both data sets separately and thereafter on a pooled data set. Tables 6 and 7 shows crude OR (COR) for the odds of experiencing physical, sexual and emotional violence, with regard to a series of key demographic variables for each period. Differences between the two studies were examined using a pooled data set constructed by combining both data sets with identical variables and adding a dummy variable to represent the time period when the data were collected. Adjusted ORs were calculated for each type of violence, including the dummy variable, while controlling for the demographic variables.

In the analysis of lifetime physical violence (table 6), having a university education was protective in the 1995 sample, but not in the 2016 study, and living in the urban area increased risk in the 2016 but not in the 1995 sample (likely due to the imputed values for zone). Having separated from her partner was associated with increased odds of IPV in the 2016 study. In the 1995 study, there was no association between age and lifetime experiences of physical partner experience. In contrast, the odds of lifetime physical violence in the 2016 study were nearly five times higher among older women (40 to 49) compared with young women ${ }^{15-19}$ (COR 4.87; $95 \%$ CI 1.68 to $14 \cdot 08$ ).

These bivariate associations remained significant in the pooled data set. Using a dummy variable to represent the time period of the study, the odds of experiencing physical violence in the 2016 study were significantly lower than in the 1995 study (COR 0.32; 95\% CI 0.24 to $0 \cdot 41$.) When controlling for the potential confounding variables, the difference between the studies was still significant (AOR $0 \cdot 37 ; 95 \%$ CI $0 \cdot 28$ to $0 \cdot 49$ ). Age, urban residence, university education and partnership status remained significantly associated with IPV in the multivariate model.

With regard to lifetime sexual violence no demographic variables were associated with the odds of violence. Time period was associated with lower odds of sexual violence in the bivariate pooled analysis $(\mathrm{COR}=0 \cdot 7,95 \% \mathrm{CI} 0 \cdot 51$ to $1.0)$, but not in the multivariate analysis.

In the analysis of 12-month physical partner violence (table 7), only partnership status was associated with greater odds of violence in the 1995 study, and none of the demographic variables were associated with IPV in the 2016 study. In the pooled analysis, women in the 2016 study had a greatly reduced odds of violence compared with women in the earlier study (COR $0 \cdot 23$; $95 \%$ CI $0 \cdot 17$ to $0 \cdot 32)$. In the multivariate model, this association was maintained (AOR $0 \cdot 29 ; 95 \%$ CI $0 \cdot 20$ to $0 \cdot 42$ ).

The findings were similar in the case of lifetime and current emotional violence. The difference between the time periods remained significant in multivariate analysis in both cases (for lifetime emotional violence AOR 0.34; $95 \%$ CI 0.26 to 0.46 and 12 -month emotional violence $\mathrm{AOR}=0 \cdot 49 ; 95 \%$ CI 0.37 to $0 \cdot 65$ ).

\section{DISCUSSION}

This study found a $63 \%$ drop in the lifetime prevalence of physical IPV over two decades, and a $71 \%$ decrease in 12-month prevalence of physical IPV. Similar decreases were also found in lifetime and 12-month emotional IPV. Surprisingly, given the large decreases in physical violence, no significant changes were found in the prevalence of sexual partner violence.

The results of the multivariate modelling indicate that the reduction in violence was not due primarily to demographic shifts, such as increased education or age, but reflects a true decrease in the prevalence of IPV. To our knowledge, this is the first study to document trends in IPV over a 20-year time frame, while controlling for potential confounding factors.

The enormous decrease in current (12-month) IPV is particularly noteworthy, and suggests that the experiences of younger women may be driving the change. In most settings, younger women report less lifetime IPV and greater 12-month IPV than older women. ${ }^{28}$ However, in Nicaragua, the opposite has occurred. In the 1995 study, there was no association between age and lifetime or current experiences of violence. This was partially explained in further analysis showing that IPV started 
Table 6 Risk factors for lifetime experiences of intimate partner violence among women age 15 to 49 from 1995 to 2016 in León, Nicaragua

\begin{tabular}{|c|c|c|c|}
\hline $\begin{array}{l}1995 \text { study bivariate } \\
\text { analysis }\end{array}$ & $\begin{array}{l}2016 \text { study bivariate } \\
\text { analysis }\end{array}$ & $\begin{array}{l}\text { Pooled data bivariate } \\
\text { analysis }\end{array}$ & $\begin{array}{l}\text { Pooled data } \\
\text { multivariate analysis }\end{array}$ \\
\hline COR $(95 \% \mathrm{Cl})$ & COR (95\% Cl) & COR $(95 \% \mathrm{Cl})$ & AOR $(95 \% \mathrm{Cl})$ \\
\hline
\end{tabular}

\section{Lifetime physical violence}

Time

\begin{tabular}{|c|c|c|c|c|}
\hline 1995 & & & 1.00 & 1.00 \\
\hline 2016 & & & $0.32(0.24$ to 0.41$)$ & $0.37(0.28$ to 30.49$)$ \\
\hline \multicolumn{5}{|l|}{ Age group } \\
\hline $15-19$ & 1.00 & 1.00 & 1.00 & 1.00 \\
\hline $20-29$ & 1.48 (0.68 to 3.24$)$ & 2.60 (0.90 to 7.57$)$ & 1.45 (0.82 to 2.56$)$ & 2.11 (1.10 to 4.03$)$ \\
\hline $30-39$ & 1.60 (0.72 to 3.56$)$ & 3.93 (1.36 to 11.38$)$ & 1.83 (1.03 to 3.24$)$ & 2.72 (1.42 to 5.24$)$ \\
\hline $40-49$ & 1.50 (0.64 to 3.52$)$ & $4.87(1.68$ to 14.08$)$ & 1.89 (1.06 to 3.37$)$ & 2.90 (1.50 to 5.63$)$ \\
\hline \multicolumn{5}{|l|}{ Zone } \\
\hline Rural & 1.00 & 1.00 & 1.00 & 1.00 \\
\hline Urban & 1.18 (0.75 to 1.86$)$ & 2.13 (1.52 to 2.98$)$ & 1.79 (1.38 to 2.32$)$ & 1.84 (1.37 to 2.46$)$ \\
\hline \multicolumn{5}{|l|}{ Education } \\
\hline None/primary & 1.00 & 1.00 & 1.00 & 1.00 \\
\hline Secondary & 0.90 (0.58 to 1.38$)$ & 1.15 (0.82 to 1.61$)$ & 0.90 (0.70 to 1.17$)$ & 0.90 (0.67 to 1.21$)$ \\
\hline University & $0.27(0.08$ to 0.89$)$ & 0.72 (0.47 to 1.11$)$ & $0.43(0.30$ to 0.63$)$ & $0.47(0.31$ to 0.71$)$ \\
\hline \multicolumn{5}{|l|}{ Partnership status } \\
\hline Currently partnered & 1.00 & 1.00 & 1.00 & 1.00 \\
\hline Formerly partnered & 1.17 (0.64 to 2.11$)$ & 1.75 (1.17 to 2.61$)$ & 1.56 (1.12 to 2.16$)$ & 1.48 (1.05 to 2.10$)$ \\
\hline \multicolumn{5}{|c|}{ Lifetime sexual violence } \\
\hline \multicolumn{5}{|l|}{ Study period } \\
\hline 1995 & & & 1.00 & 1.00 \\
\hline 2016 & & & 0.70 (0.51 to 0.96$)$ & 0.78 (0.55 to 1.11$)$ \\
\hline \multicolumn{5}{|l|}{ Age group } \\
\hline $15-19$ & 1.00 & 1.00 & 1.00 & 1.00 \\
\hline 20-29 & 0.83 (0.33 to 2.12$)$ & 1.09 (0.41 to 2.90$)$ & 0.89 (0.46 to 1.75$)$ & 0.90 (0.44 to 1.82$)$ \\
\hline $30-39$ & 1.20 (0.48 to 3.02$)$ & 1.09 (0.40 to 2.95$)$ & 1.11 (0.57 to 2.17$)$ & 1.13 (0.56 to 2.28$)$ \\
\hline $40-49$ & 1.10 (0.44 to 2.79$)$ & 1.00 (0.34 to 2.95$)$ & $1.0(0.50$ to 1.98$)$ & 1.04 (0.51 to 2.15$)$ \\
\hline \multicolumn{5}{|l|}{ Zone } \\
\hline Rural & 1.00 & 1.00 & 1.00 & 1.00 \\
\hline Urban & 1.10 (0.62 to 1.96$)$ & 1.35 (0.90 to 2.02$)$ & 1.29 (0.93 to 1.79$)$ & $1.22(0.85$ to 1.75$)$ \\
\hline \multicolumn{5}{|l|}{ Education } \\
\hline None/primary & 1.00 & 1.00 & 1.00 & 1.00 \\
\hline Secondary & 0.97 (0.57 to 1.65$)$ & 1.22 (0.79 to 1.88$)$ & 1.06 (0.76 to 1.47$)$ & 1.046 (0.73 to 1.51$)$ \\
\hline University & 0.58 (0.13 to 2.70$)$ & 1.13 (0.67 to 1.89$)$ & 0.89 (0.57 to 1.39$)$ & 0.87 (0.52 to 1.44$)$ \\
\hline \multicolumn{5}{|l|}{ Partnership status } \\
\hline Currently partnered & 1.00 & 1.00 & 1.00 & 1.00 \\
\hline Formerly partnered & 1.34 (0.66 to 2.74$)$ & 1.51 (1.01 to 2.25$)$ & 1.58 (0.97 to 2.56$)$ & 1.46 (0.98 to 2.19$)$ \\
\hline \multicolumn{5}{|c|}{ Lifetime emotional violence } \\
\hline \multicolumn{5}{|l|}{ Study period } \\
\hline 1995 & & & 1.00 & 1.00 \\
\hline 2016 & & & $0.31(0.23$ to 0.40$)$ & $0.34(0.26$ to 0.46$)$ \\
\hline
\end{tabular}


Table 6 Continued

\begin{tabular}{|c|c|c|c|c|}
\hline & $\begin{array}{l}1995 \text { study bivariate } \\
\text { analysis }\end{array}$ & $\begin{array}{l}2016 \text { study bivariate } \\
\text { analysis }\end{array}$ & $\begin{array}{l}\text { Pooled data bivariate } \\
\text { analysis }\end{array}$ & $\begin{array}{l}\text { Pooled data } \\
\text { multivariate analysis }\end{array}$ \\
\hline & COR $(95 \% \mathrm{Cl})$ & COR $(95 \% \mathrm{Cl})$ & COR (95\% Cl) & AOR $(95 \% \mathrm{Cl})$ \\
\hline \multicolumn{5}{|l|}{ Age group } \\
\hline $15-19$ & 1.00 & 1.00 & 1.00 & 1.00 \\
\hline 20-29 & 1.02 (0.43 to 2.41$)$ & 1.124 (0.57 to 2.24$)$ & 0.92 (0.56 to 1.52$)$ & 1.02 (0.59 to 1.75$)$ \\
\hline $30-39$ & 0.95 (0.40 to 2.26$)$ & 1.83 (0.92 to 3.65$)$ & 1.22 (0.74 to 2.02$)$ & 1.39 (0.80 to 2.41$)$ \\
\hline $40-49$ & 1.11 (0.43 to 2.87 ) & $1.61(0.81$ to 3.20$)$ & 1.04 (0.63 to 1.74$)$ & 1.24 (0.71 to 2.18$)$ \\
\hline \multicolumn{5}{|l|}{ Zone } \\
\hline Rural & 1.00 & 1.00 & 1.00 & 1.00 \\
\hline Urban & 1.07 (0.65 to 1.77 ) & 1.63 (1.23 to 2.17$)$ & 1.52 (1.20 to 1.93$)$ & $1.45(1.14$ to 1.96$)$ \\
\hline \multicolumn{5}{|l|}{ Education } \\
\hline None/primary & 1.00 & 1.00 & 1.00 & 1.00 \\
\hline Secondary & 0.75 (0.47 to 1.20$)$ & 1.19 (0.87 to 1.62$)$ & $0.90(0.70$ to 1.15$)$ & 0.93 (0.70 to 1.23$)$ \\
\hline University & 0.52 (0.18 to 1.53$)$ & 0.93 (0.64 to 1.34$)$ & $0.58(0.42$ to 0.80$)$ & $0.68(0.47$ to 0.99$)$ \\
\hline \multicolumn{5}{|l|}{ Partnership status } \\
\hline Currently partnered & 1.00 & 1.00 & 1.00 & 1.00 \\
\hline Formerly partnered & 1.19 (0.61 to 2.31$)$ & $1.93(1.31$ to 2.84$)$ & 1.72 (1.24 to 2.39$)$ & 1.65 (1.17 to 2.32$)$ \\
\hline
\end{tabular}

Crude ORs and adjusted ORs and 95\% Cls are shown for the odds of ever experiencing violence in their lifetimes, or in the last 12 months by an intimate partner among ever-married women aged 15 to 49. Data are shown for the 1995 and 2016 data sets individually and for a pooled data set. Figures in bold are statistically significant at the $95 \%$ level (Cl does not include 1.0).

AOR, adjusted OR; COR, crude OR.

early in relationships $(50 \%$ of violence began during the first 2 years of the relationship, and $80 \%$ within the first 4 years) and lasted throughout a women's reproductive years. ${ }^{4}$ In the 2016 study, older women report more lifetime IPV, in line with global patterns, but past year IPV is still no more frequent among younger women. The current findings indicate that the overall decrease is partly due to a cohort effect, in that younger women both marry later (a protective factor for IPV), experience less partner violence and leave violent relationships sooner than their counterparts in the 1995 study.

The only other country to our knowledge with a documented reduction in IPV prevalence is the USA, where the Justice Department reported a 63\% decrease in IPV victimisation (unadjusted) between 1994 to $2012 .{ }^{30} 31$ This decrease is widely attributed to the effects of the Violence against Women Act of 1994, which has spent over 8 billion US $\$$ in grants to local and state governments and NGOS to improve services and justice for victims of violence. ${ }^{3233}$ That Nicaragua, the second poorest country in the Western Hemisphere, shows a comparable reduction in IPV to the USA, is a stunning achievement.

Although the results show a statistically significant decrease of IPV over time, it is not possible to attribute the decrease to any specific intervention or policy. One possible explanation, supported by the qualitative findings, is that the decrease is due to multisectoral efforts by the Nicaraguan government, international donors and civil society, spurred by the women's movement, to increase women's knowledge of their rights, as well as access to justice and services for survivors. The legal and policy reforms outlined above began around the time of the first study in 1995, meaning that domestic violence was already illegal when the younger women in the 2016 study were growing up. These reforms continued throughout the 1990's and early 2000's, despite the rule of conservative political parties; another indication of the strong influence of the women's movement over social policies, bolstered by international support, particularly from Nordic donors.

That these changes did not extend to sexual violence is noteworthy. One explanation could be that a much greater emphasis was placed, both in campaigns, laws and policies, on addressing physical, rather than sexual violence. Another possibility is simply that sexual violence and men's belief in their right to control women's bodies, both within intimate relationships, as well as in public spaces, workplaces and schools, is so deeply entrenched that it is more intractable to change.

The study has some limitations that may have introduced bias. One of these is the missing values for residence that were imputed in the re-entered data from 1995. Another source of potential bias is that the 2016 collected data from women aged 15 to 64 , but only those aged 15 to 49 were included in the analysis. However, we believe that the effects of this on the overall findings are likely to be minimal.

A strength of this research is that both the 1995 and 2016 surveys were conducted by the same research team using the same master sample and design. The main difference 
Table 7 Risk factors for 12-month physical and emotional intimate partner violence among women aged 15 to 49 from 1995 to 2016 in León, Nicaragua

\begin{tabular}{|c|c|c|c|}
\hline $\begin{array}{l}1995 \text { study bivariate } \\
\text { analysis }\end{array}$ & $\begin{array}{l}2016 \text { study bivariate } \\
\text { analysis }\end{array}$ & $\begin{array}{l}\text { Pooled data bivariate } \\
\text { analysis }\end{array}$ & $\begin{array}{l}\text { Pooled data } \\
\text { multivariate analysis }\end{array}$ \\
\hline COR $(95 \% \mathrm{Cl})$ & COR $(95 \% \mathrm{Cl})$ & COR $(95 \% \mathrm{Cl})$ & AOR $(95 \% \mathrm{Cl})$ \\
\hline
\end{tabular}

\section{2-month physical violence}

Study period

\begin{tabular}{|c|c|c|c|c|}
\hline 1995 & & & 1.00 & 1.00 \\
\hline 2016 & & & $0.23(0.17$ to 0.32$)$ & 0.29 (0.20 to 0.42$)$ \\
\hline \multicolumn{5}{|l|}{ Age group } \\
\hline $15-19$ & 1.00 & 1.00 & 1.00 & 1.00 \\
\hline $20-29$ & 1.03 (0.45 to 2.36$)$ & 1.88 (0.43 to 8.22$)$ & 0.99 (0.51 to 1.93$)$ & 1.43 (0.66 to 3.11$)$ \\
\hline 30-39 & 0.70 (0.30 to 1.66$)$ & 1.70 (0.38 to 7.50$)$ & 0.75 (0.38 to 1.49$)$ & 1.16 (0.53 to 2.55$)$ \\
\hline $40-49$ & 0.61 (0.24 to 1.56$)$ & $1.86(0.42$ to 8.21$)$ & 0.65 (0.32 to 1.31$)$ & 1.04 (0.46 to 2.36$)$ \\
\hline \multicolumn{5}{|l|}{ Zone } \\
\hline Rural & 1.00 & 1.00 & 1.00 & 1.00 \\
\hline Urban & 0.96 (0.58 to 1.59$)$ & $1.48(0.87$ to 2.53$)$ & 1.28 (0.90 to 1.82$)$ & 1.31 (0.89 to 1.94$)$ \\
\hline \multicolumn{5}{|l|}{ Education } \\
\hline None/primary & 1.00 & 1.00 & 1.00 & 1.00 \\
\hline Secondary & 0.98 (0.61 to 1.57$)$ & 1.01 (0.59 to 1.73$)$ & 0.82 (0.59 to 1.15$)$ & 0.87 (0.59 to 1.27$)$ \\
\hline University & 0.17 (0.02 to 1.34$)$ & 0.65 (0.32 to 1.33$)$ & 0.31 (0.17 to 0.58$)$ & $0.43(0.22$ to 0.85$)$ \\
\hline \multicolumn{5}{|l|}{ Partnership status } \\
\hline Currently partnered & 1.00 & 1.00 & 1.00 & 1.00 \\
\hline Formerly partnered & 0.44 (0.20 to 0.99$)$ & 1.54 (0.83 to 2.86$)$ & 0.93 (0.58 to 1.51$)$ & 0.87 (0.53 to 1.44$)$ \\
\hline \multicolumn{5}{|c|}{ 12-month emotional violence } \\
\hline \multicolumn{5}{|l|}{ Study period } \\
\hline 1995 & & & 1.00 & 1.00 \\
\hline 2016 & & & $0.41(0.31$ to 0.53$)$ & $0.49(0.37$ to 0.65$)$ \\
\hline \multicolumn{5}{|l|}{ Age group } \\
\hline $15-19$ & 1.00 & 1.00 & 1.00 & 1.00 \\
\hline $20-29$ & $0.86(0.40$ to 1.87$)$ & 0.82 (0.40 to 1.69$)$ & $0.76(0.45$ to 1.27$)$ & 0.82 (0.47 to 1.41$)$ \\
\hline $30-39$ & 0.60 (0.27 to 1.32$)$ & 0.81 (0.39 to 1.67) & 0.65 (0.38 to 1.09$)$ & 0.71 (0.41 to 1.25$)$ \\
\hline $40-49$ & $0.49(0.21$ to 1.17$)$ & 0.54 (0.26 to 1.13$)$ & $0.43(0.25$ to 0.74$)$ & 0.47 (0.26 to 0.83$)$ \\
\hline \multicolumn{5}{|l|}{ Zone } \\
\hline Rural & 1.00 & 1.00 & 1.00 & 1.00 \\
\hline Urban & 1.28 (0.80 to 2.40$)$ & 1.32 (0.94 to 1.85$)$ & 1.36 (1.04 to 1.78$)$ & 1.54 (1.14 to 2.08$)$ \\
\hline \multicolumn{5}{|l|}{ Education } \\
\hline None/primary & 1.00 & 1.00 & & 1.00 \\
\hline Secondary & 1.17 (0.76 to 1.80$)$ & $1.18(0.82$ to 1.68$)$ & $1.04(0.80$ to 1.36$)$ & 0.98 (0.73 to 1.32$)$ \\
\hline University & $0.21(0.05$ to 0.96$)$ & 0.77 (0.45 to 1.21$)$ & 0.50 (0.34 to 0.75$)$ & 0.53 (0.34 to 0.82$)$ \\
\hline \multicolumn{5}{|l|}{ Partnership status } \\
\hline Currently partnered & 1.00 & 1.00 & 1.00 & 1.00 \\
\hline Formerly partnered & $0.44(0.23$ to 0.85$)$ & 0.89 (0.56 to 1.41$)$ & 0.72 (0.49 to 1.05$)$ & 0.68 (0.46 to 1.00$)$ \\
\hline
\end{tabular}

Crude and Adjusted Odds Ratios and 95\% Confidence Intervals are shown for the odds of experiencing violence ever in their lifetimes, or in the last 12 months by an intimate partner among ever-married women aged 15-49. Data are shown for the 1995 and 2016 data sets individually and for a pooled data set. Figures in bold are statistically significant at the $95 \%$ level (Cl does not include 1.0.). AOR, adjusted OR; COR, crude OR. 
between the two studies is the instrument used to collect data on violence. However, the content and wording of the instruments are very similar. If anything, the WHO survey used in 2016 might be expected to increase disclosure of violence, as it was designed specifically for an international context. The differences between the DHS and the León surveys are more likely to be due to methodological issues. Previous combined analysis of the 1995 study and the 1998 DHS suggested that the large differences in IPV reporting could be the result of methodological inconsistencies, such as interviewer recruitment, training and supervision, privacy during interviews and length of the questionnaire. ${ }^{21}$ Subsequent DHS results reported progressively lower IPV estimates, but it was not clear whether this was due to an actual decrease or under-reporting. The DHS estimates are consistently lower than both the 1995 and 2016 studies; however, the direction of the change provides additional support for our conclusions.

Despite the encouraging results, recent events in Nicaragua show how fragile these gains can be. In 2016, during the fieldwork for this study, the Comisarias de la Mujer y la Niñez were closed down by the government without explanation. ${ }^{34}$ In April, 2018, shortly before the findings of this study were to be presented in Nicaragua, the national police opened fire with live ammunition on students protesting social security reforms. To date, over 325 individuals have been killed, and over 2000 wounded, most of them unarmed protesters. Over 60000 Nicaraguans, including health professionals and researchers who collaborated in this study, are currently in exile due to threats against their lives. ${ }^{35} 36$ Women's rights defenders have been prominent in the opposition movement calling for election reforms and justice for those who were killed or arbitrarily detained. They have warned of an increase in domestic violence and femicides, due to the generalised impunity and social violence that currently reigns in Nicaragua. ${ }^{37} 38$ Urgent calls to the Nicaraguan Government have been made by the international community to re-establish the rule of law, and to reinstate protections and justice for victims of violence.

\section{CONCLUSION}

The results of this study have important implications for global policy and programmes. The findings show that it is possible to prevent violence against women and girls on a large scale through structural interventions, including multisectoral strategies that increase access to justice and comprehensive services for survivors and transform restrictive gender norms. However, from the available evidence, it is not possible to tease out which programmes and policies contributed the most to violence prevention. Moreover, it appears that the changes were more successful in reducing physical and emotional violence than sexual IPV. More research is needed to understand the effectiveness of specific strategies, in order to guide future investments and global policy on violence prevention.

Acknowledgements The authors gratefully acknowledge the contributions of Francisco Centeno, Scarlette Téllez, Lizyen Miranda, Marianela Saldaña Calderón in the supervision of field work and data analysis. Naeemah Abrahams and Mathieu Maheu-Giroux provided valuable comments on earlier drafts of this paper. Finally, the authors gratefully acknowledge the women of León, Nicaragua, who generously shared their experiences.

Contributors ME, WU and MQ contributed to the study design, data collection, analysis and interpretation and drafting the manuscript. $\mathrm{AB}$ and $\mathrm{JO}$ contributed to analysis, interpretation and drafting report. All authors have reviewed the final manuscript prior to submission.

Funding Funding was received from the Sexual Violence Research Initiative through the South African Medical Research Council.

Competing interests None declared.

Patient and public involvement Patients and/or the public were involved in the design, or conduct, or reporting or dissemination plans of this research. Refer to the Methods section for further details.

\section{Patient consent for publication Not required.}

Ethics approval The 1995 study received ethical approval from the Ethical Review Board of the Medical Faculty at UNAN-León and the 2016 study received approval from the Institutional Review Boards of the George Washington University and UNANLeón.

Provenance and peer review Not commissioned; externally peer reviewed.

Data availability statement Data are available on request from the corresponding author.

Open access This is an open access article distributed in accordance with the Creative Commons Attribution Non Commercial (CC BY-NC 4.0) license, which permits others to distribute, remix, adapt, build upon this work non-commercially, and license their derivative works on different terms, provided the original work is properly cited, appropriate credit is given, any changes made indicated, and the use is non-commercial. See: http://creativecommons.org/licenses/by-nc/4.0/.

\section{ORCID iD}

Mary Ellsberg http://orcid.org/0000-0003-0666-5196

\section{REFERENCES}

1 Devries KM, Mak JYT, García-Moreno C, et al. Global health. the global prevalence of intimate partner violence against women. Science 2013;340:1527-8.

2 Ellsberg M, Arango DJ, Morton M, et al. Prevention of violence against women and girls: what does the evidence say? Lancet 2015;385:1555-66.

3 Ellsberg MC, Peña R, Herrera A, et al. Wife abuse among women of childbearing age in Nicaragua. Am J Public Health 1999;89:241-4.

4 Ellsberg M, Peña R, Herrera A, et al. Candies in hell: women's experiences of violence in Nicaragua. Soc Sci Med 2000;51:1595-610.

5 Garcia-Moreno C, Jansen HAFM, Ellsberg M, et al. Prevalence of intimate partner violence: findings from the who multi-country study on women's health and domestic violence. The Lancet 2006;368:1260-9.

6 WHO/FCH/GWH/01.1, Distribution: General. Putting Women's Safety First: Safety and Ethical Recommendations for Researching Violence against Women, 2002.

7 Kishor S, Subaiya L. Understanding women's empowerment: a comparative analysis of Demographic and Health Surveys (DHS) data, 2008.

8 Asling-Monemi K, Peña R, Ellsberg MC, et al. Violence against women increases the risk of infant and child mortality: a casereferent study in Nicaragua. Bull World Health Organ 2003;81:10.

9 Olsson A, Ellsberg M, Berglund S, et al. Sexual abuse during childhood and adolescence among Nicaraguan men and women: a population-based anonymous survey. Child Abuse Negl 2000:24:1579-89.

10 Valladares E, Ellsberg M, Peña R, et al. Physical partner abuse during pregnancy: a risk factor for low birth weight in Nicaragua. Obstet Gynecol 2002;100:700-5. 
11 Valladares E, Peña R, Ellsberg M, et al. Neuroendocrine response to violence during pregnancy--impact on duration of pregnancy and fetal growth. Acta Obstet Gynecol Scand 2009;88:818-23.

12 Ellsberg M, Liljestrand J, Winkvist A. The Nicaraguan network of women against violence: using research and action for change. Reprod Health Matters 1997;5:82-92.

13 Mujer INdela. INIM). Plan Nacional para La prevención de la violencia intrafamiliar Y sexual, Nicaragua 2001-2006. Managua, Nicaragua: INIM, 2000.

14 Jubb N, Camacho G, D'Angelo A, et al. Access to justice for women in situations of violence: A comparative study of women's police stations in Latin America. IDRC, CEPLAES, 2008.

15 Solorzano I, Bank A, Pena R, et al. Catalyzing personal and social change around gender, sexuality, HIV: Impact evaluation of Puntos de Encuentro's communication strategy in Nicaragua. Puntos de Encuentro; CIDS/UNAN Leon; PATH; Horizons Program, 2008.

16 Sudduth C, D'Amico M. Law 779: addressing violence against women in Nicaragua. Ark J Soc Change Public Serv, 2014.

17 Neumann PJ, Governance T. Local politics, and gender violence law in Nicaragua. Lat Am Polit Soc 2018;60:61-82.

18 Rosales J, Loiaza E, Primante D, et al. Encuesta nacional de demografía y salud [Internet]. Managua: Instituto Nacional de Estadística y Censos, 1998. http://www.econis.eu/PPNSET?PPN= 25647883X

19 Instituto Nacional de Informacion de Desarrollo. Encuesta Nicaraguense de Demografía Y Salud 2006/2007. Managua, Nicaragua: INEC, 2008.

20 Instituto Nacional de Informacion de Desarrollo. Encuesta Nicaraguense de Demografía Y Salud 2011/2012. Managua, Nicaragua: INEC, 2013.

21 Ellsberg M, Heise L, Peña R, et al. Researching domestic violence against women: methodological and ethical considerations. Stud Fam Plann 2001;32:1-16.

22 Straus MA. Measuring intrafamily conflict and violence: the conflict tactics (CT) scales. J Marriage Fam 1979;41:75-88.

23 World Health Organisation. WHO Questionnaire on Women's Health and Domestic Violence against Women. Version 12.2. Geneva: WHO, 2016.
24 INIDE. Anuario Estadistico 2016. Managua, Nicaragua: Instituto Nacional de Informacion de Desarrollo (INIDE), 2019

25 Peña R, Pérez W, Meléndez M, et al. The Nicaraguan health and demographic surveillance site, HDSS-Leon: a platform for public health research. Scand J Public Health 2008;36:318-25.

26 Ellsberg M, Heise L. Bearing witness: ethics in domestic violence research. Lancet 2002;359:1599-604.

27 Little RJA, Rubin DB. Statistical analysis with missing data. John Wiley \& Sons, 2014: 358.

28 Abramsky T, Watts $\mathrm{CH}$, Garcia-Moreno $\mathrm{C}$, et al. What factors are associated with recent intimate partner violence? findings from the who multi-country study on women's health and domestic violence. BMC Public Health 2011;11:109.

29 Heise LL, Kotsadam A. Cross-National and multilevel correlates of partner violence: an analysis of data from population-based surveys. Lancet Glob Health 2015;3:e332-40.

30 Catalano S. Intimate partner violence, 1993-2010. U.S. department of justice, Bureau of justice statistics, 2012: 17

31 Truman JL. Nonfatal domestic violence, 2003-2012. U.S. department of justice, Bureau of justice statistics, 2014: 21.

32 Modi MN, Palmer S, Armstrong A. The role of violence against women act in addressing intimate partner violence: a public health issue. J Womens Health 2014;23:253-9.

33 Sacco LN. The violence against women act (VAWA): historical overview, funding, and reauthorization. 42, 2019.

34 Medie P, Walsh S. International organizations, nongovernmental organizations, and police implementation of domestic violence laws in Liberia and Nicaragua. Polit Gend, 2019.

35 Inter-American Commission on Human Rights. Gross human rights violations in the context of social protests in Nicaragua. Washington D.C.: IACHR, 2018.

36 Agren D. Criminalisation of health care in Nicaragua's political crisis. Lancet 2018;392:807-8.

37 Inter-American Commission on Human Rights. IACHR concerned about ongoing repression in Nicaragua. Washington D.C: IACHR, 2019.

38 Romero K. The Nicaragua crisis means increased violence against women. Confidencial Nicaragua, 2020. 